اهميت رعايت تناسب كاربرى اراضى در توليد رواناب و رسوب در حوضه آبخيز بهشتآباد استان جهارمحال و بختيارى

دلارام ضيايى جزى "، رفعت زارع بيدكى'، على اصغر بسالتيور ' و آرش ملكيانَ

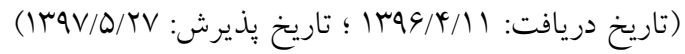

جكيده



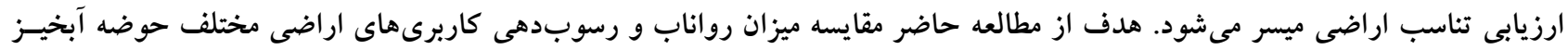

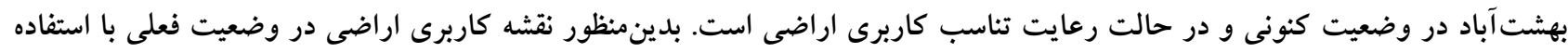

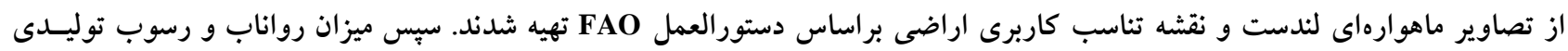

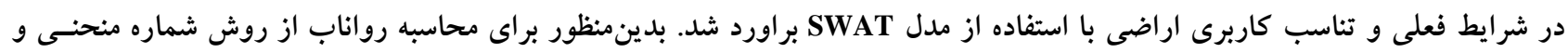

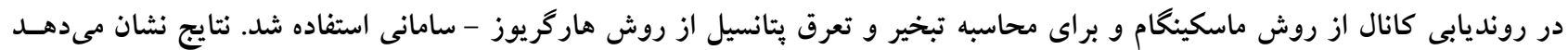

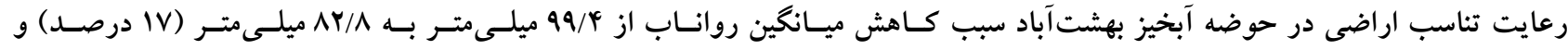



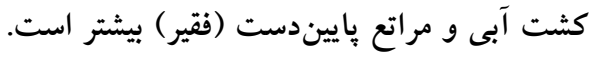

وازههاى كليدى: تناسب اراضى، رواناب، فرسايش، SWAT،FAO

ا. أكروه مرتع و آبخيزدارى، دانشخاه شهركرد

r. مؤسسه مديريت منابع، برلين، آلمان

r. كروه احياء مناطق خشك و كوهستانى، دانشكاه تهران

D_ziaei@yahoo.com : مسئول مكاتبات: پِّت الكترونيكى 


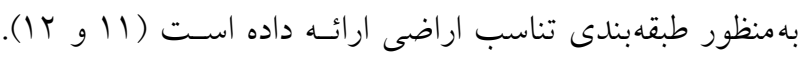



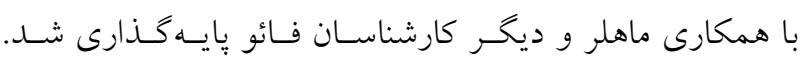



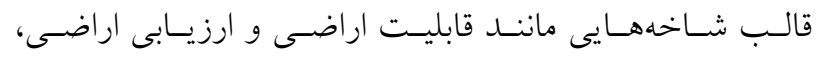





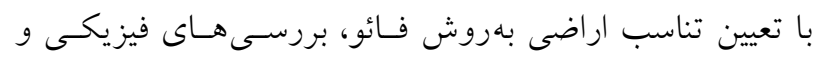

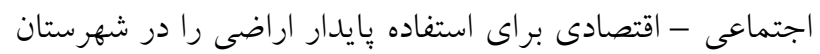

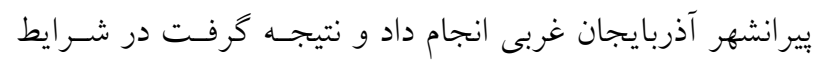

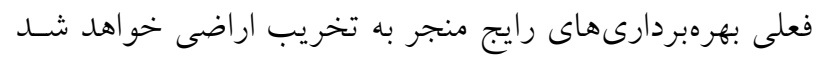

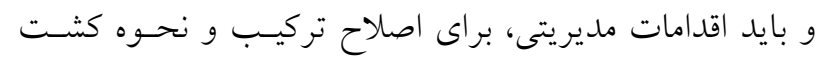


تالو در اندونزى با كمك مدل RUSLE و اطلاعات اقليم، خاك، شيب، كاربرى زمين و شيوههاى حفاظـت خـاك، از اطلاعـات

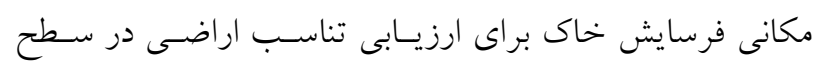

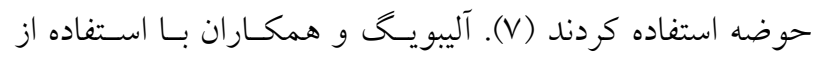

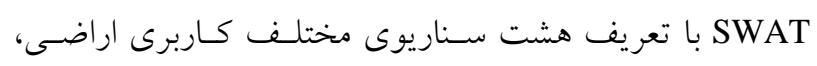
توليد جريان و بار رسوبى حوضه مانويالى را شبيه سازى كردند.

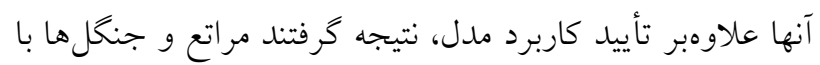

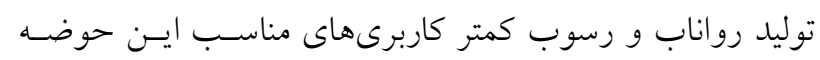

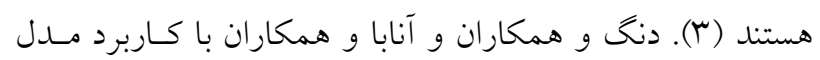

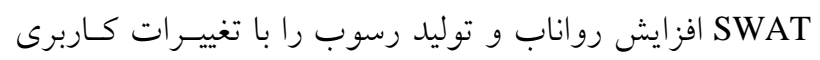

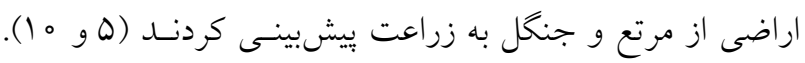

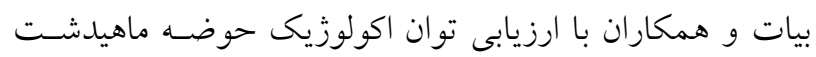


مشخص كردند در شرايط بهينه مساحت جنخـلهــاى منطقـه از

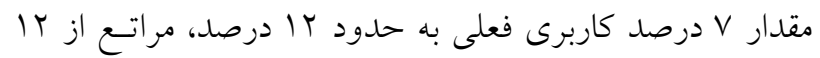

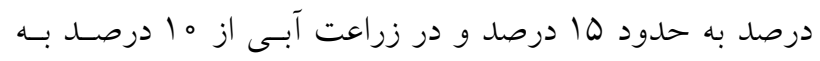
حدود م9 درصد افزايش مى يابند (N). تاكنون مطالعات زيـادى در زمينه تناسب اراضى صورت گرفته است، اما كمتر مطالعهاى

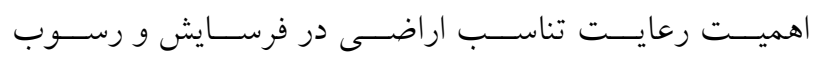

محيط زيست طبيعى، توان اكولوزيكى محدودى بـراى استففاده

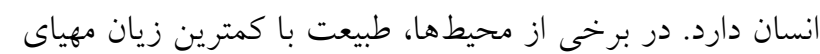

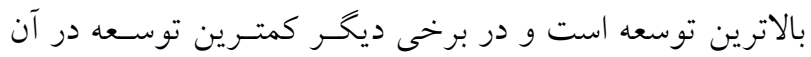

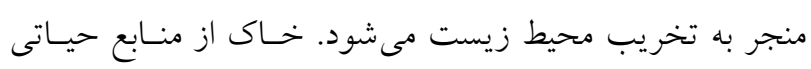

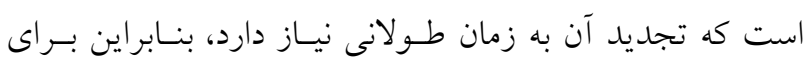

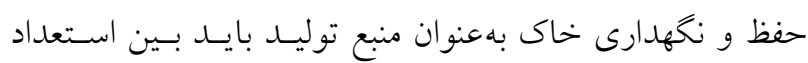



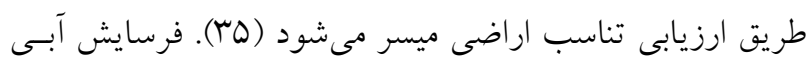

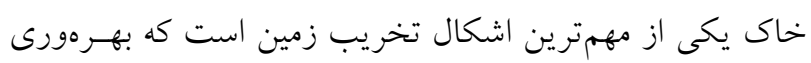

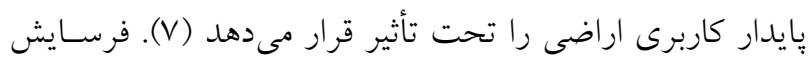

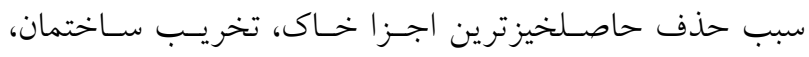



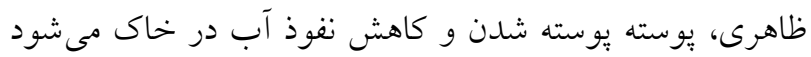



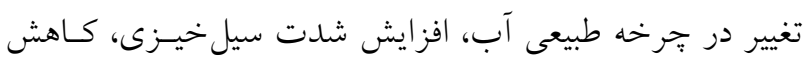

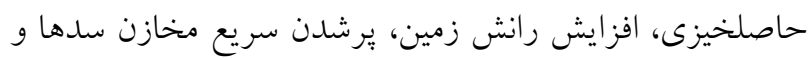





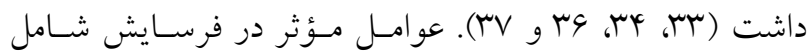

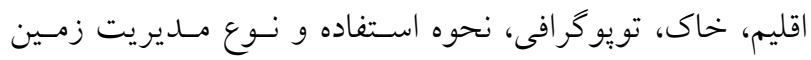

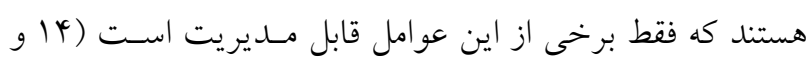
IV

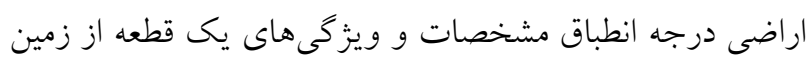

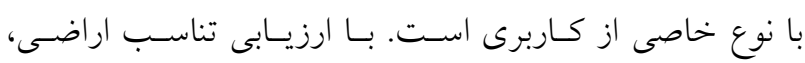

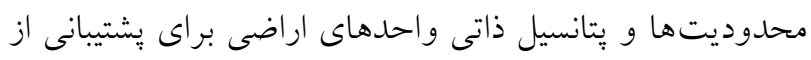

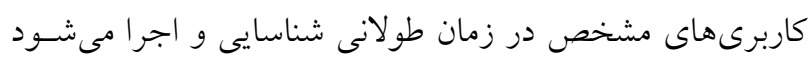

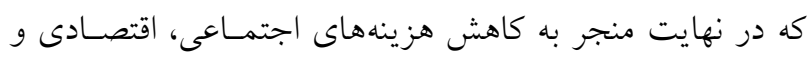

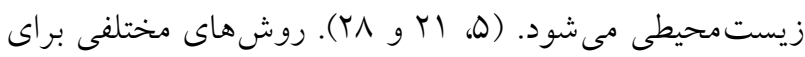

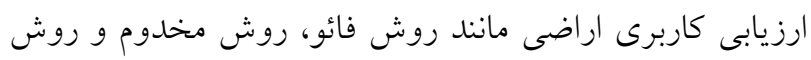



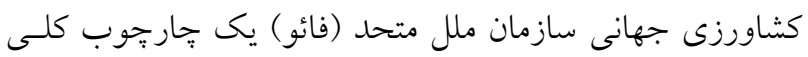




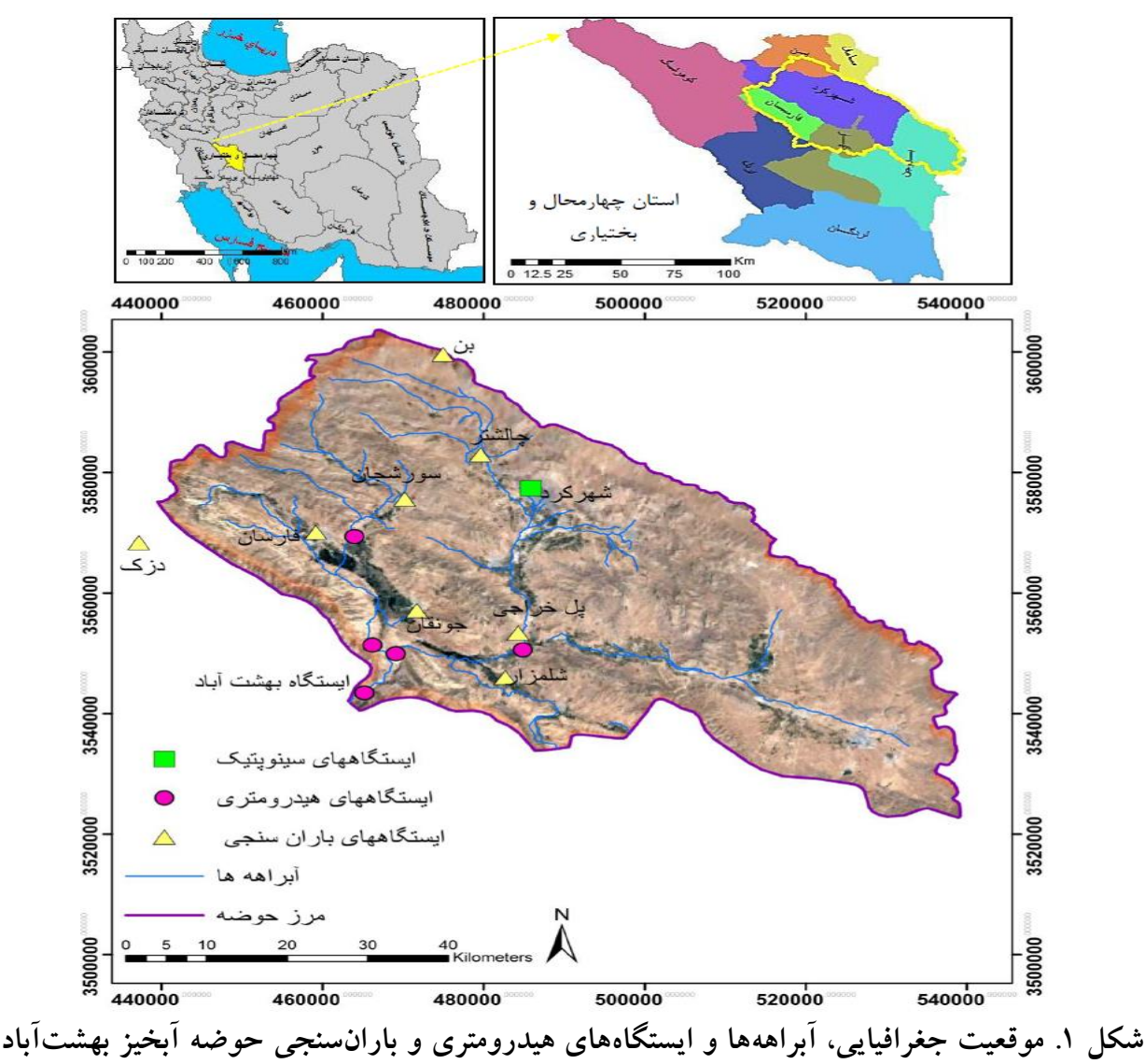

ا 1 ا درجه سانتى گراد است. از نظـر زمسينشناسى داراى دو

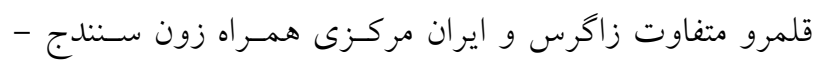

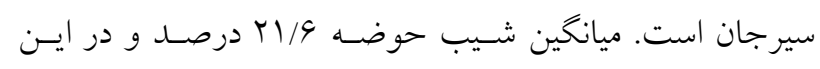



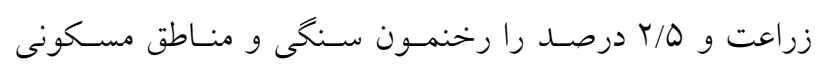




جغر افيايى حوضه بهشت آباد را نشان مى مهديد.

\section{مدل SWAT}

مـدل SWAT (Soil \& Water Assessment Tool) يـك مـدل نيمهتوزيعى فيزيكى است كه قادر به هـيشبينس تـأثير عمليـات

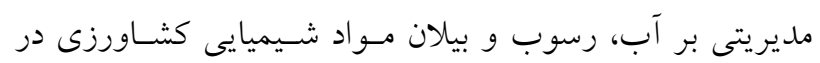

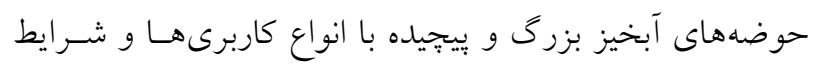

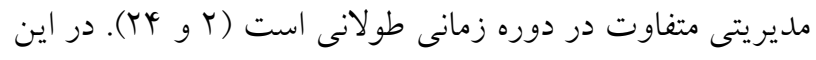

را به لحاظ كمّى بررسى كرده است. حوضه بهشتآباد بهدليل داشتن

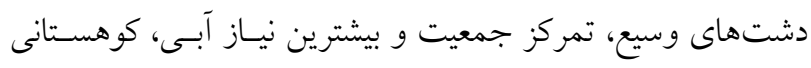

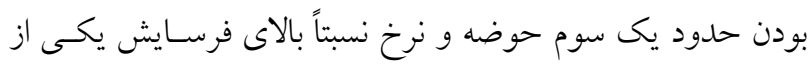

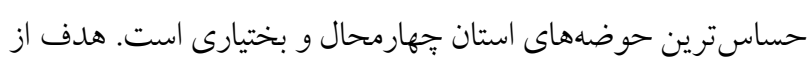

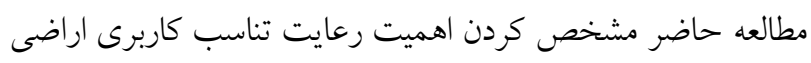

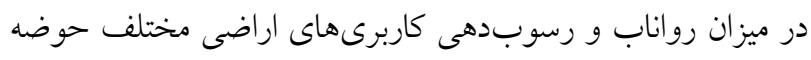
آبخيز بهشت آباد است.

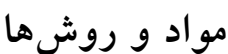

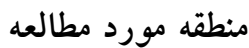

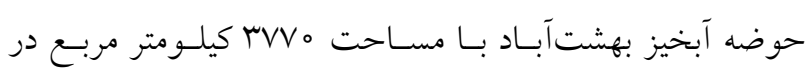

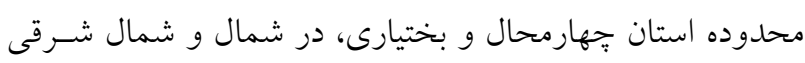

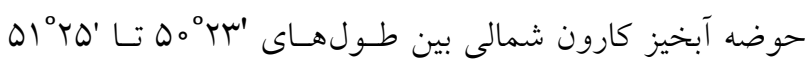

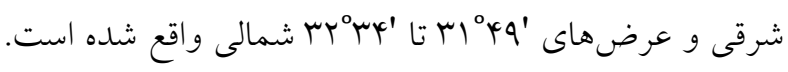




فرايندهاى هيـدرولوزيكى اهميـت دارد ( آY). بنـابر اين كـاهش





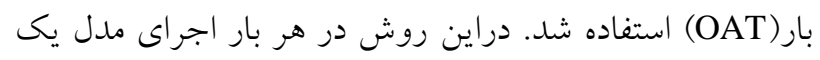

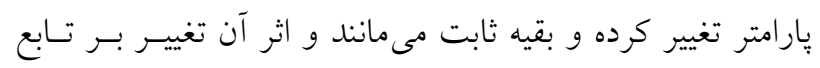
هدف، حساسيت يارامتر را مشخص مى كند. بـهمنظـور ارزيسابى

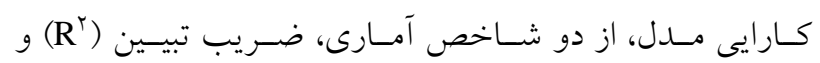
راندمان نش - سـاتكليف (NS) و و p-factor و استفاده شد. ضريب تبيين بين صفر تا يكى تغيير مى كند و مقدار بهينه آن

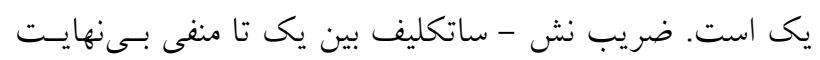



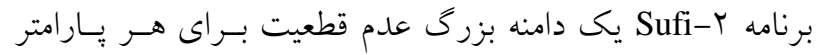

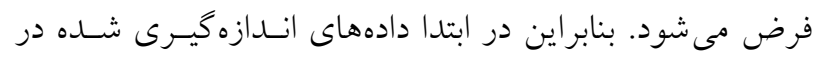

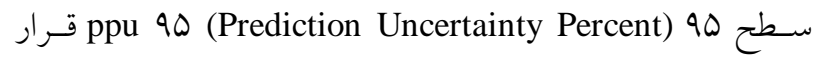
مى گيرند و سبس اين عدمقطعيت در خـامهـاى متـوالى كـاهش

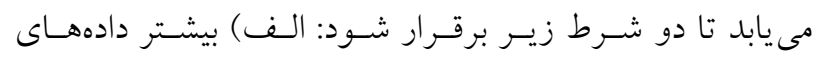



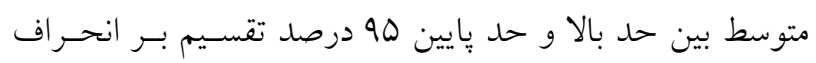

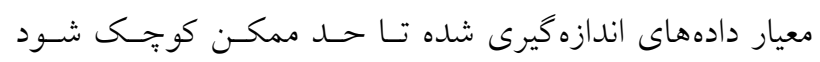

(1) r-factor) (1r)

\section{تهيه نقشه كاربرى اراضى كنونى و نقشه تناسب كاربرى اراضى} بهمنظور مدلسازى رواناب و رسـوب بـا مـــ SWAT، نقشـهـ كاربرى اراضى منطقه با استفاده از تصاوير سنجنده لندست Vو و با تركيب سه باند جهار، سه و دو (نوارهاى مادون قرمز نزديك، قرمز و سبز) در محيط نرم|فزار ILWIS و بـهروش طبقهـبنـدى نظارتشده، تهيه شد. سبس با توجه به نقشههاى موجود قبلى و كنترلهاى ميدانى و تصاوير Google Earth اصلاح و بـهنـــوان يكى از ورودىهاى اصلى مدل استفاده شد. بهمنظور تهيه نقشـه

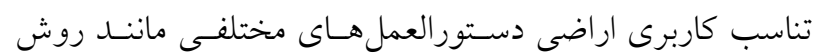

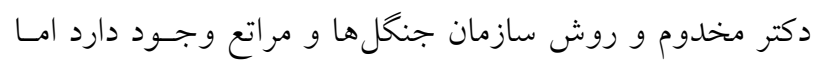

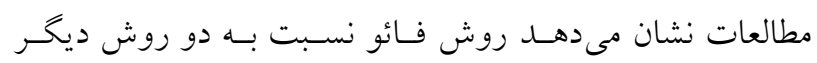

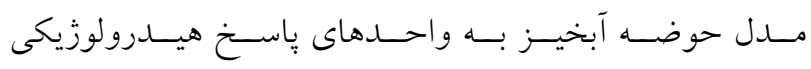
كه بهلحاظ كاربرى اراضسى و (Hydrological Response Unit) ويزگى هاى خاك و شيب همخن هستند، تفكيك مى شود. بـراى

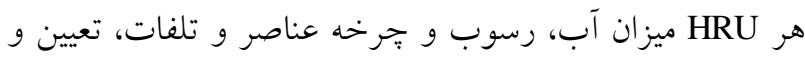

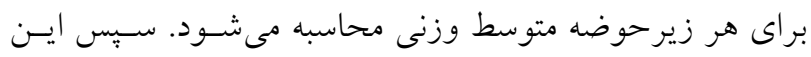

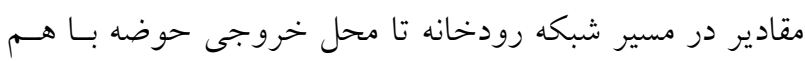

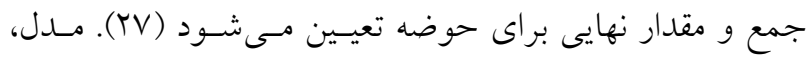


ييشبينى مى كند. رواناب سطحى در اين مدل با دو روش شماره

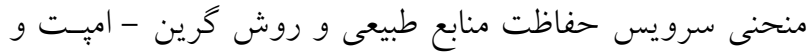
تبخير و تعرق را با استفاده از سه روش بريستلى تيلور، ينمن -

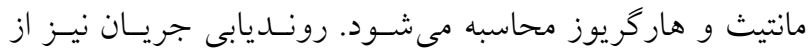

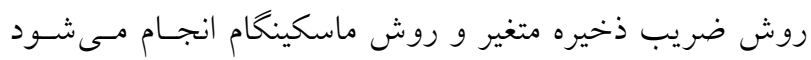

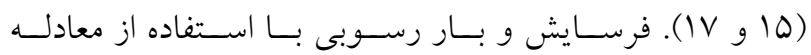

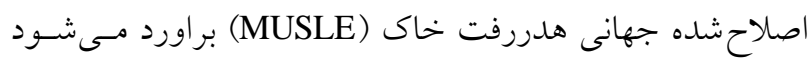

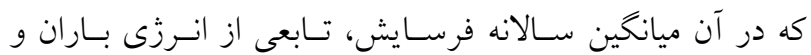

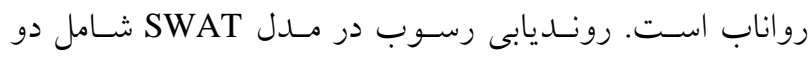


همزمان در كانال فعال هستند. اين دو فرايند با استفاده از ابعـاد كانال براى كل كانال توسط مدل شبيهســازى مسى شــوند. مقــدار

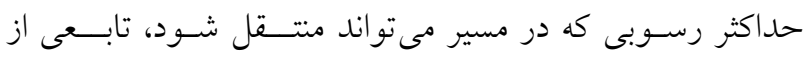



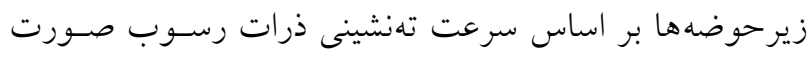

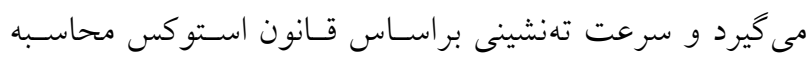

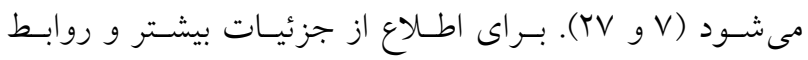

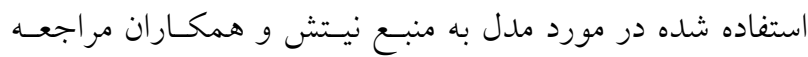

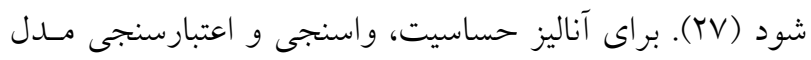

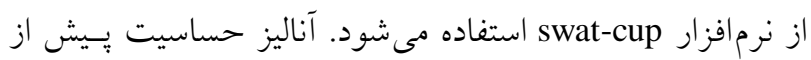
واسنجى مدل راهنمايى براى تعيين دامنه تغييرات يارامترهاسـت

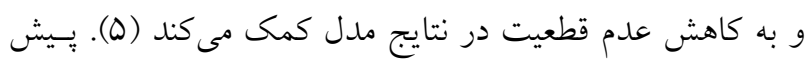

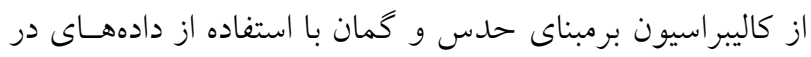

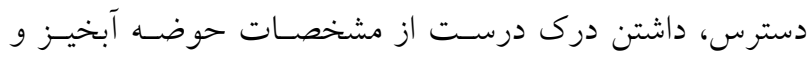


جدول ا. كلاسهاى محدوديت تناسب اراضى (FAO)

\begin{tabular}{|c|c|c|c|}
\hline شيب (درصد) & سنگ وسنگريزه سطحى (درصد) & 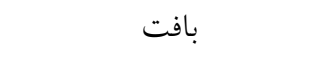 & كلاس محدوديت \\
\hline$\Delta-\circ$ & 10-r & خيلى درشت (S) & 1 \\
\hline$\Lambda-\infty$ & $r \Delta-10$ & درشت (SL, LS) & r \\
\hline $\mid r-\Lambda$ & $V \Delta-r \Delta$ & سبك (SL, L, SiL) & r \\
\hline rD-IT & $<V Q$ & متوسط (L, SL, SiL) & r \\
\hline$<T Q$ & - & سنخين (SiCL, SCL, CL) & $\Delta$ \\
\hline- & - & خيلى سنخين (C, SC, SiC) & 4 \\
\hline
\end{tabular}



تعيين ميزان رسوبدهى در وضعيت كنونى و شرايط اسـتاندارد با استفاده از مدل SWAT يس از تهيه نقشه كاربرى اراضى و تناسب اراضى، شـبيهسـازى رواناب و رسوب با مدل SWAT انجام شد. ابتدا مــل رقل رقـومى ارتفــاعى (DEM) بــا دقـت مكــانى ه ا متــر بــراى تفكيـك

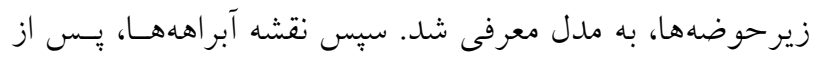
اصلاح روى تصاوير Google Earth به مدل خوانده شد. يس از تعيين مرز حوضه آبخيز با توجه به تويوگرافى و شبكه آبراههها

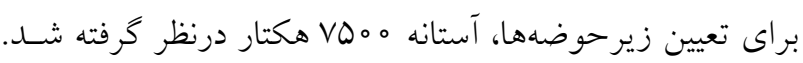
اطلاعات مربوط به ايستخاههـاى هيـدرومترى (outlet point) و جشمهها (point source) بهصـورت جــاولى بـه مــل وارد و و درنهايت اس زيرحوضه مجزا مرزبنـدى شـد. يسس از آن نقشـه كاربرى اراضى و خاكشناسى به مدل فراخوانده شد. با توجه بـهـ شيب ميانه ش/ T درصد، شيب منطقه در دو كلاس طبقهبندى و مقادير آستانه براى خاى، كاربرى اراضى و شـيب يــنج درصــ

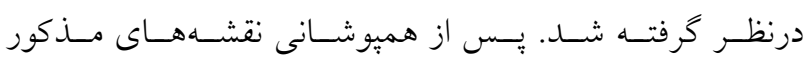
زيرحوضه ها به ب4 و واحد بِاسخ هيدرولوزيك در كـل حوضسه تقسيم شدند. در نهايت دادههاى اقليمى شامل بـارش روزانـه و حداقل و حداكثر دماى روزانه براى دوره هr سـاله از ra 199 تـا Y Y T آمار ه ا ايستخاه بارانسنجى و هواشناسى واقع در حوضه به مدل وارد شد. بهدليل كمبود اطلاعات اقليمى طـولانى مـدت براى تابش خورشيدى، رطوبت نسـبى و سـرعت بـاد، از روش
سختخيرانهتر عمل مى كند، بنابراين محدوديت كـاربرى اراضسى ارائه شده توسط 9V9)FAO (9V9) مبناى كار قرار كرفـت. بـا تهيـه

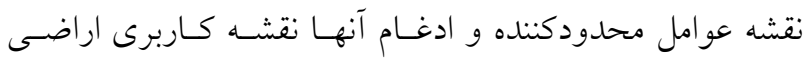


مطالعات خاكشناسى در حوضه كارون شمالى، اراضسى حوضـه بهشت آباد بهلحاظ شورى (EC)، قلياييت خاى (SAR) و عمـق خاك محدوديتى نداشتند، تهيه نقشه تناسب اراضى تنها براساس سه عامل بافـت، درصــ سـنگ و ســخر يزه و شـيب صـورت كرفت. كلاسهاى محدوديت شيب و بافت و سنگ و سنخريزه اعمال شده به شرح جدول (1) است (IT). عامل تعيين كننده براى كشت ديم، بارندكى است. با توجه به نقشه خطوط همباران منطقه، محدوديتى از اين نظـر بـهـــز در محدوده كوجكى از جنوب شرقى منطقه (متوسط بارش سـالانه كمتر از ه مب ميلى متر) مشاهده نشد كـه منطقـه مـذكور نيـز بـا توجه به محدوديت شـيب جـزء اراضسى مناسـب كشـت قـرار

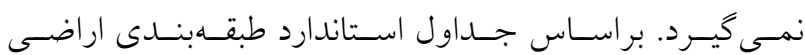
دستورالعمل FAO، نقشـه محسـوديت حاصـل از مرحلـه قبـل مجدداً طبقهبندى شده و اراضى مناسب هريك از كـاربرىهـاى

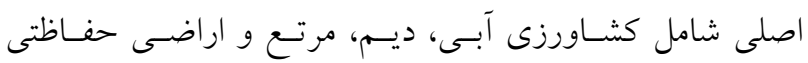
مشخص شد. در اين مطالعه با توجه به هدف يـزوهش كـه بـــ حداقل رساندن ميزان رسوب حاصل از فرسـايش خـاك اسـت اراضى با شيب بالاى ه V درصد جـزو منـاطق حفـاظتى درنظـر كرفته شده اسـت. جـدول (Y) اسـتانداردهاى (Y MV9) Mahler) براساس يار امترهاى شيب زمين، عمق خاى و منبع تأمين آب را 
جدول r. راهنماى تهيه نقشه تناسب اراضى (Mahler, 1979)

\begin{tabular}{|c|c|c|c|c|}
\hline \multicolumn{3}{|c|}{ عمق خاى ( سانتىمتر ) } & \multirow{2}{*}{ وضعيت منابع آب } & \multirow{2}{*}{ طبقه شيب (درصد) } \\
\hline زياد (40) & متوسط (ro-rop) & كم (ro-0) & & \\
\hline آبى - باغ & * & * & بلدون محدوديت & \\
\hline ديم - باغ & ديم - باغ & * & محدوديت متوسط & $\Delta-\circ$ \\
\hline ديم & ديم & $*$ & فاقد آب آبيارى & \\
\hline آبى - باغ & * & * & بلدون محدوديت & \\
\hline ديم - باغ & $*$ & * & محدوديت متوسط & $\wedge-\Theta$ \\
\hline ديم & ديم & $*$ & فاقد آب آبيارى & \\
\hline * & * & * & بدون محدوديت & \\
\hline ديم - باغ & ديم - باغ & $*$ & محدوديت متوسط & $\mid r-\Lambda$ \\
\hline ديم & ديم، ديم - بادامكارى & $*$ & فاقد آب آبيارى & \\
\hline \multirow{3}{*}{ ديم، ديم - بادام كارى } & * & * & بدون محدوديت & \\
\hline & ديم - باغ & $*$ & محدوديت متوسط & rQ-IT \\
\hline & ديم، ديم - بادامكارى & مرتع & فاقد آب آبيارى & \\
\hline مرتع & * & $*$ & بدون محدوديت & \\
\hline مرتع & $*$ & $*$ & محدوديت متوسط & $r \Delta<$ \\
\hline مرتع & مرتع & مرتع & فاقد آب آبيارى & \\
\hline
\end{tabular}

با استفاده از پيارامترهاى حساس بهينه در مرحله اعتبارسـنجى و واسنجى در وضعيت كنـونى، در SWAT-CUP بـا يـك مرتبـه تكرار كاليبره و نتايج براى شرايط استاندارد از خروجسى مـدل براى هر كاربرى خوانده شد. در اين مطالعـه محـدوديت عـدم تغيير كاربرى اراضى ملى براى توسعه اراضى درنظر كرفته نشده است. فرض بر اين است كه وسعت كـاربرىهـاى مختلـف بـه ميزان تعيين شده در نقشه تناسب اراضى قابل تغييرند.

\section{نتايج}

نقشه كاربرى اراضى حوضـه آبخيـز بهشــآبــاد بـا اسـتفاده از

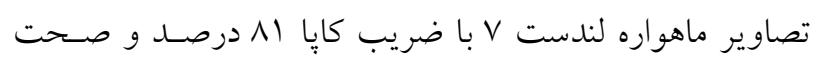





شكل (r). (1).
هارگريوز - سامانى براى محاسبه تبخير و تعرق پِانسيل استفاده

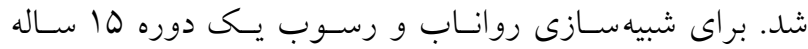
(Y0| T-199V) آموزش (Warm up) مدل استفاده و مدل اجرا شد. در محاسبـه رواناب از روش شماره منحنـى و در رونـديابى كانـال از روش ماسكينگام استفاده شد. يّ از ساخت مدل يار امترهاى حساس مدل بر جريان آبراهه و رسوب، توسط آناليز حساسيت شناسايى

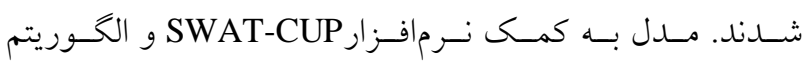
بهينهسازى SUFI-Y، بـا اسـتفاده از همــه يارامترهـاى حسـاس

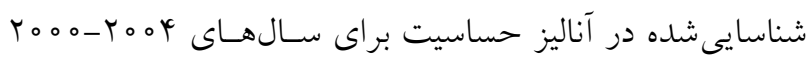

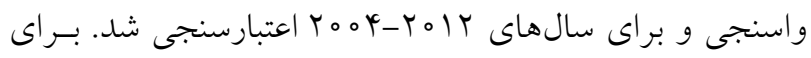
تعيين ميزان توليد رواناب و رسـوب هـر كـاربرى در وضـعيت رعايت استاندارد اراضى، در مرحله معرفى نقشه كابرى اراضسى لئى به مدل نقشه تناسب اراضى تهيه شده به مدل معرفى شد و مدل 



جدول r. مساحت و درصد كاربرىهاى اراضى حوزه آبخيز بهشتآباد در وضعيت كنونى و وضعيت استاندارد

\begin{tabular}{|c|c|c|c|c|}
\hline \multicolumn{2}{|c|}{ وضعيت استاندارد } & \multicolumn{2}{|c|}{ وضعيت كنونى } & \multirow{2}{*}{ كاربرى } \\
\hline درصد & مساحت (هكتار) & درصد & مساحت (هكتار) & \\
\hline YY & $q \circ r_{\circ} \circ$ & $10 / 1$ & $\Delta V \circ \circ \circ$ & راضى كشت آبى و آيش آبى \\
\hline $19 / \pi$ & 91040 & $4 / 9$ & $1 \wedge 0 \circ \circ$ & اراضى كشت ديم \\
\hline $10 / 4$ & «Nץ০。 & - & - & اراضى كشت ديم - باغ \\
\hline$\omega / \vee$ & r|r|。 & $r / Q$ & $90 \circ \circ$ & باغ \\
\hline $11 / 0$ & ( & $10 / 1$ & ץへ००。 & مراتع خوب( بالادست ) \\
\hline $11 / V$ & Fetoo & $10 / 9$ & 90000 & مراتع متوسط( ميانبند ) \\
\hline $19 / 4$ & $V \mu \circ \circ$ & $0 \circ / 1$ & 1199000 & مراتع ضعيف( ياييندست ) \\
\hline
\end{tabular}

كشت ديم درنظر كرفته شد. از •ه يـارامتر مـورد بررسسى،

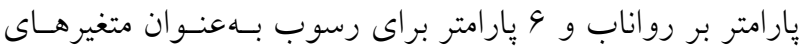
مؤثر بر شبيهسـازى جريـان و رسـوب در حوضـه بهشتـآ بــاد شناسايى شدند (1) (1) جدول (Y) نتايج حاصل اعتبارسنجى و واسنجى ملدل را بـراى حوضه در دو حالت وضـعيت كنـونى و رعايـت تناسـب كـاربرى اراضى نشان مىدهد. نتايج شبيهسازى توليد روانـاب و رسـوب در
جدول (r) مساحت كاربرىهاى مختلف اراضى را در وضـعيت كنونى و بعد از استانداردسازى كاربرى اراضى نشان مى دهد. در اين مطالعسه بخشـى از اراضسى كـه در وضـعيت كنـونى تحـت كاربرى مرتع قرار دارند با هر دو نوع كاربرى باغ و كشت ديـم متناسب است كه در شبيهسازى رواناب و رسوب با استفاده از نقشه تناسب اراضى و با توجه به درآمل بيشتر باغ و محدوديت

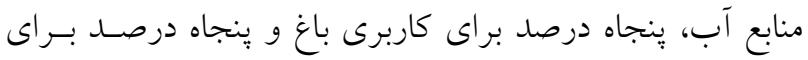


جدول f. جتايج كاليبر اسيون مدل SWAT

\begin{tabular}{|c|c|c|c|c|c|c|c|c|}
\hline \multicolumn{4}{|c|}{ اعتبار سنجى (validation) } & \multicolumn{4}{|c|}{ واسنجى (calibration) } & \\
\hline NS & $\mathrm{R}^{r}$ & $\mathrm{p}$-factor & $\mathrm{r}$-factor & NS & $\mathrm{R}^{2}$ & p-factor & $r$-factor & \\
\hline $0 / 91$ & ०/^צ & $\circ / \mathrm{VV}$ & $\circ / \Delta r$ & $\circ / N r$ & $\circ / V q$ & $0 / 94$ & $\circ / \uparrow \wedge$ & وضعيت كنونى \\
\hline $0 / 99$ & $\circ / \wedge$ & - & - & $\circ / V Y$ & $\circ / V r$ & - & - & وضعيت استاندارد \\
\hline
\end{tabular}

جدول ه. نتايج شبيه سازى توليد رواناب و رسوب در شرايط فعلى و رعايت استاندارد كاربرى اراضى در حوضه آبخيز بهشتآباد

\begin{tabular}{|c|c|c|c|c|c|c|}
\hline \multicolumn{2}{|c|}{ درصد تغييرات } & \multicolumn{2}{|c|}{ وضعيت استاندارد } & \multicolumn{2}{|c|}{ وضعيت كنونى } & \multirow[b]{2}{*}{ كاربرى } \\
\hline رسوب & رواناب & 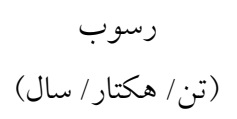 & (ميلى متر / سال) & (تن / هكتار / سال) &  & \\
\hline$-9 Y$ & $-Y V / V$ & $T / V$ & $\Delta V / \Delta$ & $V / I$ & 110 & كشت آبى \\
\hline$-V_{0}$ & $-\Delta Y$ & $\Lambda / 1$ & $9 \circ / 0$ & $T Y / D$ & 190 & كشت ديم \\
\hline$+r_{0} \circ$ & $+N / Y Q$ & $4 / q$ & $19 / 9$ & $1 / 94$ & $\Lambda_{0}$ & باغ \\
\hline$-T_{9}$ & $-10 / 4$ & $1 \% / 0$ & 110 & $1 \Lambda / r$ & $\mu \circ$ & مراتع بالادست \\
\hline$-r q / 0$ & $-V$ & $T / \Psi$ & $\Lambda r / \Delta$ & $r / 4$ & $19 / 1$ & مراتع ميانبند \\
\hline$-9 \circ$ & $-Y / \Psi$ & $\Gamma / 0$ & $\wedge \vee$ & $1 / 9$ & $\wedge \otimes$ & مراتع ياييندست \\
\hline- & - & $\mathrm{V} / \mathrm{A}$ & $\Lambda T / \Lambda$ & $10 / V$ & $99 / 4$ & ميانخين \\
\hline
\end{tabular}

1/1/0 تـن در هكتـار و روانـاب سـالانه مبا ميلـىمتـر اسـت. ديمزارهاى موجود در منطقه در شـيب نامناسـب و زيـاد واقـع شدهاند؛ ضمن اينكه در جهت شيب شخم زده مىشوند و همين عامل سبب توليد رواناب زياد و فرسايش شديد خـاك در ايـن كاربرى شده است. مراتع بالادست حوضه بهشت آباد بـا داشـتن

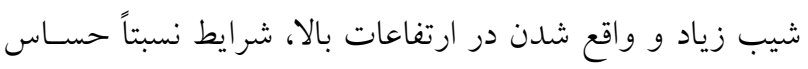

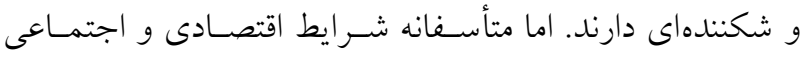

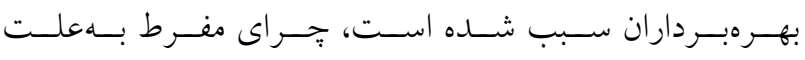
خوش خوراكى علوفه و ضعيف شدن مراتع ياييندست صـورت بحيرد. بهرهبردارى بيش از حد از مراتعى كه در جنين شـرايطى واقع هستند، سبب شده است ميزان توليد رواناب و رسـوب در آن نسبتاً زياد باشد. درنتيجه نتايج نشان مىدهد كمتـرين ميـزان

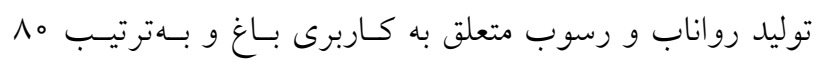
ميلى متر و سو/ا تن در هكتار در سال است. استفاده از اراضسى بهشكل باغ بهدليل اصلاح شيب بـهـصورت سـكوبندى، ايجـاد
حالت كنونى و تناسب اراضى در جدول (ه) مقايسه شده است.

\section{بحث و نتيجه كيرى}

هدف از مطالعه حاضر براورد ميزان رواناب و رسـوب توليـدى در كاربرىهاى مختلف اراضسى حوضـه بهشـتآَبـاد در حالـت كنونى و مقايسه آن با شرايطى است كه كاربرى اراضى متناسب برمبناى استعداد و ظرفيت زمين انتخاب شود. به ايسن منظـور از مدل SWAT در دو حالت استفاده شـد. در حالـت اول شـرايط موجود منطقه براساس نقشه كاربرى اراضى فعلى بـه مــل داده شد. نتايج بيانكر اين است كه در وضعيت موجود ميزان رواناب توليد شده در كل حوضه بهطور متوسط 99/4 ميلى متر و مقـدار رسوب توليدى نيز \٪/ تن در هكتار است. در وضعيت كنونى بيشترين ميزان رسوبدهى و روانـاب متعلـق بـه كـاربرىهـاى كشت ديم با توليد رسوب سالانه /Y/D تن در هكتار و روانـاب سالانه 19 ميلى متر و مراتع بالادست با توليـد رسـوب سـالانه 
فرسايش باقى خواهـــ مانـــــ در ارزيـابى تناسـب اراضسى تنهـا

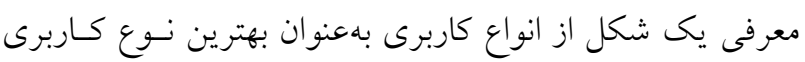





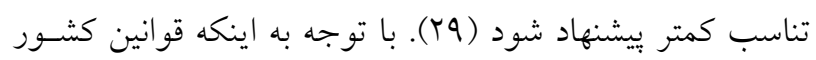

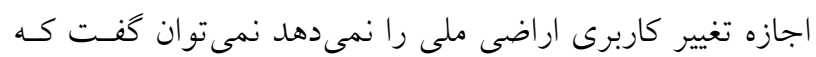

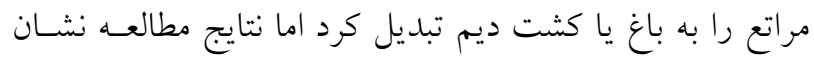



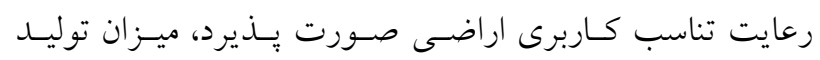
رواناب و رسوب در حوضه كاهش خواهد يافت. ضـمن اينكـه

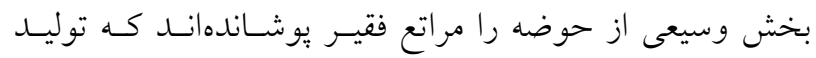
علوفه و درنتيجه بهره اقتصادى كمى دارنـــ. براسـاس مطالعـه



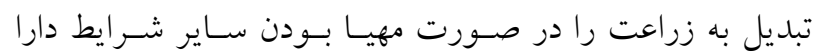

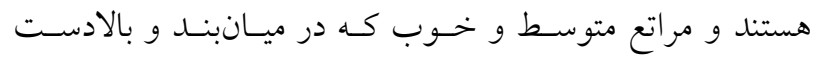
حوضه واقع شدهاند تقريباً دستنخورده باقى مىمانند. مطالعات

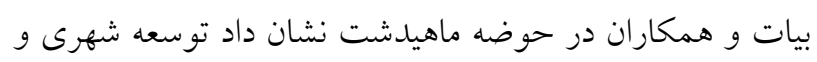

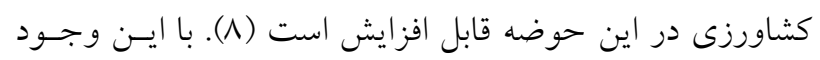

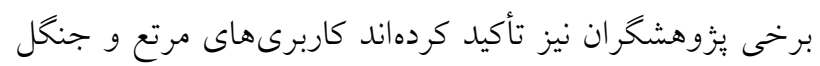

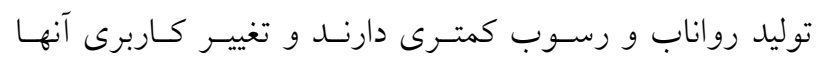

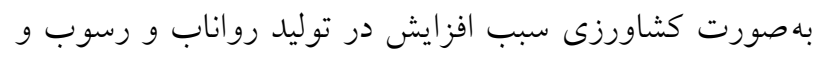


تحليل تناسب اراضى ارائه شده در اينجا نهتنها نمايانكر استفاده

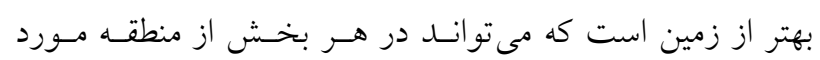

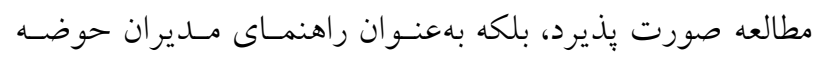

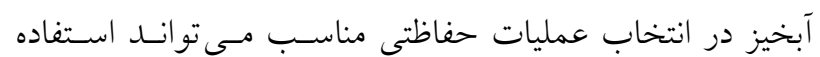

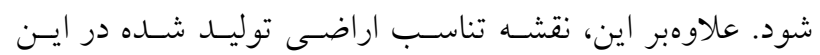



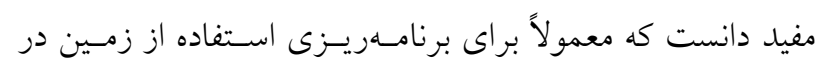

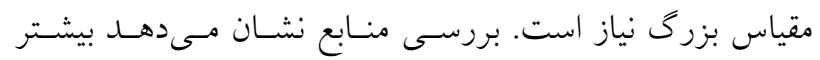


اقتصادى اراضى براى محصولات كشاورزى استراتزيك بهويـزّه
يوشش دائمى روى زمين و دستـكارى كمتـر خـاك نسـبت بـهـ

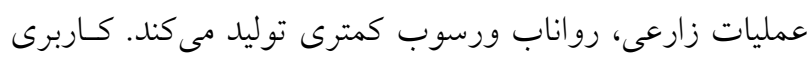

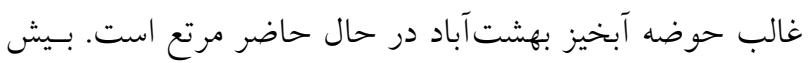

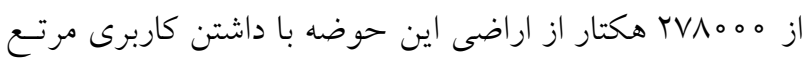
بهعنوان اراضى ملى شناخته مى شوند و دخل و تصرف در آنها آنها

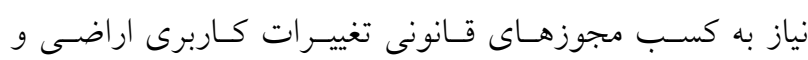
واگذارى زمين دارد. بنابراين تعيين تناسب اراضى در اين مطالعه بهائه


براساس مطالعات جامع ترى بهمنظور توسعه، تصميم به اصـلاح

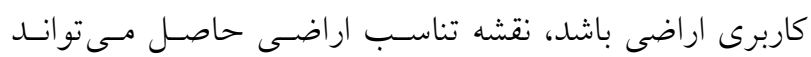

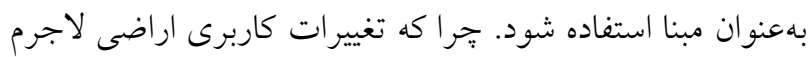

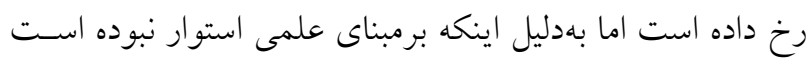

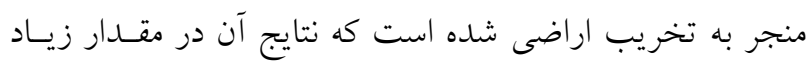

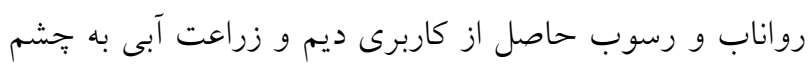

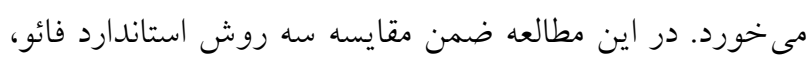

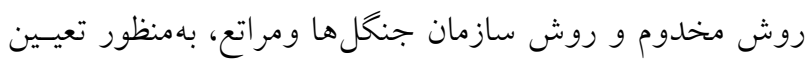

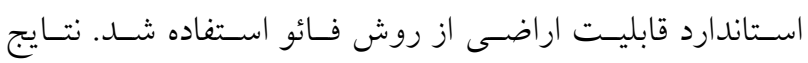

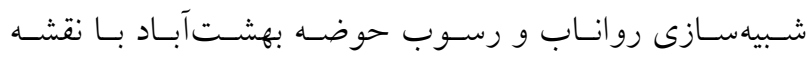

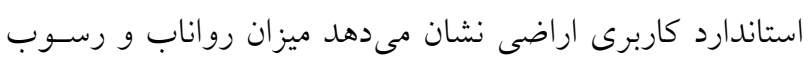
در بيشتر كاربرىهاى اراضى، بهويزه كشت ديم بـهميـزان قابـل فيل

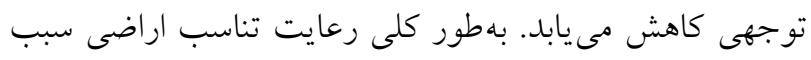

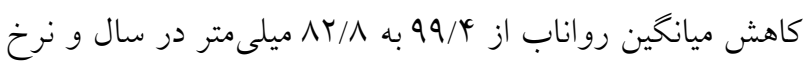



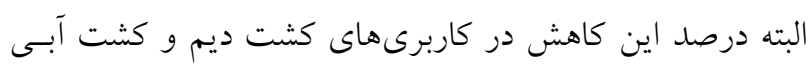


نيكى كامى و همكاران در مطالعات مشابه به اين نتيجـه رسـيدند

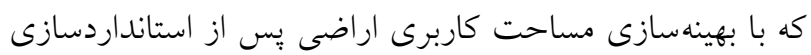
اراضى ميزان رسوبدهى كاربرىهـاى مختلـف بـهميـزان قابـل

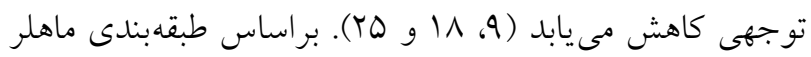
امكان توسعه باغات در اراضى تا شيب كه درصـد وجــود دارد

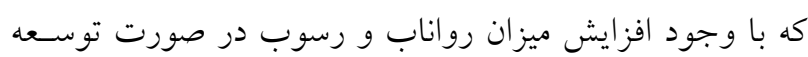
باغات تا اين حد همجنان ميزان رسوبدهى در محدوده مجـاز 


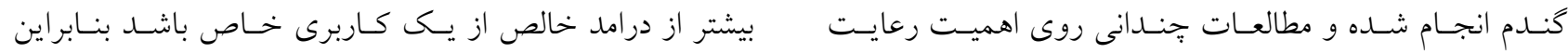



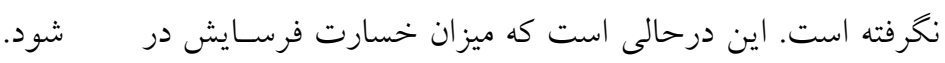

$$
\begin{aligned}
& \text { صورت عدم رعايت تناسب اراضى ممكـن اسـت حتسى بسـيار }
\end{aligned}
$$

1. Abbaspour, K. C. 2015. User manual for SWAT-CUP (SWAT Calibration and Uncertainity Programs), swiss federal institute of aquatic science and technology, Ewage. Dubendorf. Switzerland. 100p

2. Alemu, W. G., T. Amare, B. Yitaferu, Y. G. Selassie, B. Wolfgramm and H. Hurni. 2013. Impacts of soil and water conservation on land suitability to crops: the case of anjeni watershed, Northwest Ethiopia. Journal of Agricultural Science 5(2): 95-109

3. Alibuyog, N. R., V. B. Ella, M. R. Reyes, R. Srinivasan, C. Heatwole and T. Dillaha. 2009. predicting the effects of land use change on runoff and sediment yield in manupali river subwatersheds using the swat model. International Agricultural Engineering Journal 18(1-2): 15-25.

4. Amler, B., D. Betke Eger, H. Ehrich Chr, U. Hoesle, A. Kohler, C. Küsel, A. V. Lossau, W. Lutz, U. Müller, T. Schwedersky, S. Seidemann, M. Siebert, A. Trux and W. Zimmermann. 1999. Land Use Planning Methods, Strategies and Tools, Deutsche Gesellschaft für Technische Zusammenarbeit (GTZ) GmbH P.O. Box 5180, 65726 Eschborn, Germany.

5. Anaba, L. A., N. Banadda, N. Kiggundu, J. Wanyama, B. Engel and D. Moriasi. 2017. Application of SWAT to assess the effects of land use change in the murchison bay catchment in Uganda, Computational Water, Energy, and Environmental Engineering 6: 24-40.

6. Arnold, J. G., R. Srinivasan, R. S. Muttiah and J. R. Williams. 1998. Large area hydrological modeling assessment. Journal of the American Water Resources Association 34(1): 73-89

7. Baja, S. ,Nurmiaty. U., and Arif. S., . 2014. GIS-based soil erosion modeling for assessing land suitability in the urban watershed of tallo river, south sulawesi, Indonesia. Modern Applied Science 8(4): 50-60.

8. Bayat, B., A. Motkan, B. Rahmani and B. Arabi. 2011. Comprehensive land use planning and land planning in urban watersheds using gis - case study : mahidasht watershed. Journal f Management System 14(13): 119-135.

9. Davoodirad, A., D. Nikkami and M. Mardian. 2013. Land use optimization using two-objective linear programing model in Adineh Masjed Shazand watershed. Journal of Watershed Engineering and Management 5(1): 17-24.

10. Deng, Z., X. Zhang and D. L. Guoyan Pan. 2014. Simulation of land use/land cover change and its effects on the hydrological characteristics of the upper reaches of the Hanjiang Basin. Environ Earth Science 73 :1119-1128.

11. FAO. 1976. A framework for land evalouation. FAO land bulletin. 32 : ROME.

12. FAO. 1993. Guidelines for land use planning. FAO Development Series 1. Rome, Italy.

13. Faramarzi, M., K. C. Abbaspour, R. Schulin and H.Yang. 2009. Modelling blue and green water resources availability in Iran. Hydrological Processes 23: 486-501.

14. Gebel, M., M. Uhlig, S. Halbfass, R. Meissner and S. Duan. 2014. Predicting erosion and sediment yield in a mesoscale basin in the semiarid monsoon region Miyun/China. Ecological Processes 3(5): 2-11

15. Hosseini, M. 2014. Water balance simulation in Ghare-Sou Watershed, Kermanshah, using the SWAT model. Journal of Watershed Engineering and Management 6(1): 63-73.

16. Houshmand Kouchi, D., K. Esmaili, A. Faridhosseini, S. A. Sanaeinejad, D. Khalili and K. C. Abbaspour. 2017. Sensitivity of calibrated parameters and water resource estimates on different objective functions and optimization algorithms. Water 9(2): 384-400.

17. Imamoglu, A., I. D. Turan, O. Dengiz and F. Saygin. 2014. Soil erosion risk evaluation : application of corine methodology at engiz watershed, samsun. Current Advances in Environmental Science (CAES) 2(1): 15-21.

18. Jafari. A., D. Nikkami, E. Abbasi and F. Tavakoli Rad. 2013, Investigating land use schema in Sana Dam Watershed in Bushehr Province. Journal of Watershed Engineering and Managemen 5(3) : 155-164.

19. Kamaludin, H., T. Lihan, Z. Ali Rahman, M. A. Mustapha, W. M. R. Idris and S. A. Rahim. 2013. Integration of remote sensing, RUSLE and GIS to model potential soil loss and sediment yield (SY). Hydrology and Earth System Sciences 10: 4567-4596.

20. Keshavarzi, A., F. Sarmadian and A. Ahmadi. 2011. Spatially-based model of land suitability analysis using Block Kriging. Australian Journal of Crop Science 5 :1533-1541. 
21. Mahler, P. J. 1979. Manual of Land Classification for Irrigation (Third Revised Edition). Soil Instituted of Iran.

22. Manguerra H. B. and B. A. Engel. 1998. Hydrologic Parameterization of Watersheds for runoff prediction using SWAT. The American Water Resources Association 34(5): 1149-1162.

23. Naserabadi, F., A. Esmali Ouri, H. Akbari and R. Rostamian. 2016. River flow simulation using SWAT model (case study: Ghareh Su River in Ardabil Province-Iran). Journal of Watershed Management Research 7(13): 50-59.

24. Neitsch, S. L., J. G. Arnold, J. R. Kiniry, J. R. Srinivasan and J. R. Williams. 2011. Soil and Water Assessment Tool, Teorical Documentation, Version 2009, Grassland, Soil and Water Labratoary, Agricultural Research Service Blackland Research Center, Texas Agrilife University.

25. Nikkami, D., H. Chamheydar, M. H. Mahdian and E. Pazira. 2012. Land use management optimization for Abolabbas Watershed resources conservation, Journal of Watershed Engineering and Management 4(1): 51-62.

26. Nouri, H., A. Ildoromi, M. Naderi, S. Aghabeigi Amin and H. Zeinivand. 2018. Comparison of land use and climate change impacts on runoff in a small mountainous catchment (case study : garin dam catchment). Journal of Physical Geography Research 50(14): 775-790.

27. Prakash, T. N. 2003. Land Suitability Analysis for Agricultural Crops : A Fuzzy Multicriteria Decision Making Approach. MSc. Thesis. International Institute for Geoinformation Science and Earth Observation, Netherlands.

28. Rouhani, H., P. Willems and J. Feyen. 2007. Analysis of parameter sensitivity and uncertainty of the SWAT hydrological model. Hydrological Science and Technology 23 : 191-2002.

29. Shahrokh, V. and S. Ayoubi. 2014. Land suitability evaluation using analytical hierarchy process technique in Zarrinshahr and Mobarakeh (Isfahan). Journal of Agricultural Engineering 37(1): 77-92.

30. Shakeri, S. and A. Moameni. 2011. Land suitability classification for sustainable use in Aq qaleh area. Journal of Human and Environment 9(16): 21-31.

31. Sieber, A., T. Kuemmerle, A. V. Prishchepov, J. Kelly, M. Baumann, C. R. Volker and M. B. Leonid. 2013. Landsat-based mapping of post-Soviet land use change to assess the effectiveness of the Oksky and Mordovsky protected areas in European Russia. Article Remote Sensing of Environment 133: 38-51.

32. Sokoti, S. 2000. Land Suitability Assessment Tool for Sustainable Land Management, In: Proceeding of the National Conference on Land Management - Soil Erosion and Sustainable Development, Natural Resources and Livestock Research Center of Markazi Province, Soil Conservation and Watershed Management Research Center, Arak. Pp: 28-34

33. Sun, X. F., T. X. Yue and Z. M. Fan. 2012. Scenarios of changes in the spatial pattern of landuse in China Procedia Environmental Sciences 13 : 590-597.

34. Sys, C., E. Van Ranst and J. Debaveye. 1993. Land evaluation part III, crop requirements. Agricultural Publication No. 7.: General Administration for Development Cooperation, Brussels, Belgium.

35. Taleai, M., H. Soleimani and M. Farajzadeh asl. 2014. Land suitability evaluation for cultivation of wheat, based on the FAO model and fuzzy-AHP-OWA technique in GIS environment (case study : Miyaneh County). Journal of Water and Soil 28(1): 139-156.

36. Toy, T. J., Foster. G. R. and Renard. K. G . 2002. Soil Erosion: Processes, Prediction, Measurement, and Control. Technology and Engineering, WIELY Publication.

37. Wang, Q., J. Liu, Y. Wang, J. Guan, Q. Liu and D. Lv. 2012. Land use effects on soil quality along a native wetland to cropland chronosequence. Journal of Soil Biology 53: 114-120.

38. Ziaie. D., R. Zare Bidaki and A. Besalatpour. 2020. Comparing surface runoff and sediment yield of different land uses in beheshtabad watershed using SWAT. Journal of Range and Watershed Management (under publishment). 


\title{
The Importance of Land Use Suitability for Runoff and Sediment Production in Beheshtabad Basin, Chaharmahal and Bakhtiari Province
}

\author{
D. Ziaei ${ }^{1 *}$, R. Zare Bidaki ${ }^{1}$, A. A. Besalatpour ${ }^{2}$ and A. Malekian ${ }^{3}$
}

(Received: July 2-2017; Accepted: August 18-2018)

\begin{abstract}
To preserve soil as a productive resource, a balance between natural capability and utilization must be established to achieve through land suitability evaluation. The aim of this study was to compare the run-off and deposition of different land uses of Beheshtabad watershed in the current situation and in compliance with standardized land use fitted situation. For this purpose, land use map in its current state was provided using Landsat 7 images and land use suitability map was obtained by FAO (1979) instructions. SWAT model was then applied to simulate runoff and sediment yield by using these land use maps. To do this, the curve number method was used for calculating the runoff, the Muskingam was applied for channel routing, and Hrgrave-samani was employed for potansial evapotranspiration. The results confirmed that considering suitability in using lands in Beheshtabad watershed caused the reduction of the average runoff from $99.4 \mathrm{~mm} / \mathrm{yr}$ to $82.8 \mathrm{~mm} / \mathrm{yr}(17 \%)$ and sediment rate of 10.7 to $7.8 \mathrm{t} / \mathrm{ha}$. $\mathrm{yr}$ (27\%). Also, the reduction percentage in some land uses, such as dry, irrigated cropland and downstream ranges, was much more.
\end{abstract}

Keywords: Erosion, FAO, Land suitability, Runoff, SWAT

1. Range and Watershed Management Department, Shahrekord University, Shahrekord, Iran.

2. Resources Management Institute, Berlin, Germany

3. Department of Watershed Science and Management, University of Tehran, Karaj, Iran.

*: Corresponding Author, Email: D_ziaei@yahoo.com 